\title{
Prevalence and effect of oxytetracycline on congenital fetlock knuckling in neonatal dairy calves
}

\author{
Authors: \\ Mujeeb R. Fazili ${ }^{1}$ \\ Hiranya K. Bhattacharyya ${ }^{1}$ \\ Manzoor u.R. Mir \\ Abdul Hafiz ${ }^{1}$ \\ Noore A. Tufani ${ }^{1}$ \\ Affiliations: \\ ${ }^{1}$ Teaching Veterinary \\ Clinical Complex, Faculty \\ of Veterinary Sciences and \\ Animal Husbandry, \\ Sher-e-Kashmir University \\ of Agricultural Sciences and \\ Technology of Kashmir, India \\ ${ }^{2}$ Division of Veterinary \\ Biochemistry, Faculty of \\ Veterinary Sciences and \\ Animal Husbandry, \\ Sher-e-Kashmir University \\ of Agricultural Sciences and \\ Technology of Kashmir, India
}

\section{Correspondence to:}

Mujeeb Fazili

Email:

fazili_mr@yahoo.co.in

Postal address:

78-HIG (Lane 6, Green Park)

Colony, Bemina, Srinagar,

Kashmir 190018, India

Dates:

Received: 11 Nov. 2013

Accepted: 25 June 2014

Published: 12 Nov. 2014

How to cite this article: Fazili, M.R., Bhattacharyya, H.K., Mir, M.u.R., Hafiz,

A. \& Tufani, N.A., 2014,

'Prevalence and effect of oxytetracycline on congenital fetlock knuckling in neonatal dairy calves', Onderstepoort Journal of Veterinary Research 81(1), Art. \#710, 6 pages. http://dx.doi. org/10.4102/ojvr.v81i1.710

\section{Copyright:}

(C) 2014. The Authors Licensee: AOSIS OpenJournals. This work is licensed under the Creative Commons Attribution License.

\section{Read online:}

Musculoskeletal system deformities were observed in $24(34.3 \%)$ of 70 neonatal dairy calves that presented with different congenital abnormalities. Among them, 19 calves (27.1\%), the majority of which were crossbred Jersey calves of either gender with mean $( \pm$ s.e.) body weight $22.00 \mathrm{~kg}$ $\pm 1.17 \mathrm{~kg}$ and aged $7.11 \pm 1.16$ days, were presented for treatment of congenital knuckling. Five of the knuckling calves had additional concurrent congenital conditions and were excluded from the present study. All of the remaining 14 calves showing moderate, bilateral fetlock knuckling had a wooden or polyvinyl chloride (PVC) splint applied to the palmar or plantar aspect of the affected limbs. All of the animals received a dose of the analgesic tolfenamic acid intramuscularly, and were randomly allocated to two equal groups. Calves of Group I additionally received oxytetracycline $(20 \mathrm{mg} / \mathrm{kg}$ intravenous daily for 3 days). The condition resolved satisfactorily in $83.3 \%$ and $80.0 \%$ calves from the two groups, respectively. The left and right fetlock angle (mean $\pm \mathrm{SE}$ ) reduced significantly $(p \leq 0.01)$ from $50.57^{\circ} \pm 4.20^{\circ}$ to $4.00^{\circ}$ $\pm 2.27^{\circ}$ and $48.71^{\circ} \pm 2.37^{\circ}$ to $5.33^{\circ} \pm 3.03^{\circ}$, respectively in animals of Group I. In Group II calves, the angles showed reduction from $50.86^{\circ} \pm 2.94^{\circ}$ to $4.20^{\circ} \pm 2.75^{\circ}$ and from $48.71^{\circ} \pm 3.14^{\circ}$ to $6.80^{\circ}$ $\pm 3.34^{\circ}$, respectively. From the present study, it was concluded that bilateral moderate fetlock knuckling in the neonatal dairy calves can be managed satisfactorily with early application of splints. Supplementary use of oxytetracycline at repeated doses of low toxicity had only a marginally beneficial effect.

\section{Introduction}

Congenital contracted flexor tendon, observed most frequently as flexion of the metacarpophalangeal or metatarsophalangeal joint within 1 or 2 weeks of birth, is a common defect in numerous breeds of cattle (Leipold, Hiraga \& Dennis 1993; Simon et al. 2010). Aetiologic origins include inherited factors, in utero nutrition, malposition and the foetus being too large relative to the dam (Anderson, Desrochers \& St Jean 2008; Ferguson 1997). The diagnosis can easily be made by the abnormally flexed position of the affected limb. The deformity may be mild (if the calf is able to walk on the feet but the heels do not contact the ground), moderate (if the animal is able to remain standing on the tip of the toe with the dorsal aspect of the hoof lying perpendicular to the ground but walks on the dorsal aspect of the pastern, fetlock or carpus) or severe (if the affected animal stands and walks on the dorsal aspect of the pastern, fetlock or carpus). Severe flexural deformities are also accompanied by arthrogryposis, involvement of multiple limbs and the head and neck, and severe carpal deformities. The animals with flexural deformities may be unable to nurse, so failure to acquire passive immunity transfer may be a complicating factor (Weaver, St Jean \& Steiner 2005). Chronic deformity may lead to skin ulceration on the dorsum of the fetlock and, subsequently, to septic arthritis.

Successful treatment of flexural deformities depends on the site and severity of the deformity and on the appropriate use of medical, physical and, possibly, surgical therapy. Moderate cases are routinely treated by using a bandage, splint or cast and by providing analgesia (Anderson $e t$ al. 2008). Splints can be very useful for restoring the limb to normal alignment and orientation. In a new-born foal, a single high dose of oxytetracycline administered intravenously (IV) at $44 \mathrm{mg} / \mathrm{kg}$ together with the application of the splints has been reported to result in a moderate decrease in the metacarpophalangeal joint angle (Madison et al. 1994). Although oxytetracycline ( $3.0 \mathrm{~g}$ in $250 \mathrm{~mL}$ physiological saline) IV has been given in calves, its routine use at such a high single dose is not recommended because of its high nephrotoxicity (Ducharme 2004). Anderson et al. (2008) reported some success with lower doses of oxytetracycline but the details of dose and frequency of administration were not provided.

The present study was planned to determine the prevalence of congenital fetlock knuckling and to ascertain the benefit of using a low-toxicity dose of oxytetracycline continuously for 3 days supplementary to the application of splints in neonatal calves with this type of moderate bilateral deformity. 


\section{Material and methods}

Seventy newborn calves with different congenital external deformities were presented to the Teaching Veterinary Clinical Complex, Faculty of Veterinary Sciences, Sher-eKashmir University of Agricultural Sciences \& Technology of Kashmir, Shuhama, Srinagar, Kashmir, India by rural owners for treatment over a period of 3 years (2006-2008). Knuckling of the distal limb joints was detected in 19 of these calves. Fourteen (14) of the calves with moderate bilateral fetlock knuckling and without any additional deformity were included in this treatment trial. Forelimbs (Figure 1) were involved in 12 calves, and in two calves, hindlimbs (Figure 2) were affected. The physiological parameters recorded included respiration rate (RR), heart rate (HR) and rectal temperature $(\mathrm{T})$. The blood samples were assessed for packed cell volume (PCV), haemoglobin $(\mathrm{Hb})$ and total plasma protein (TPP).

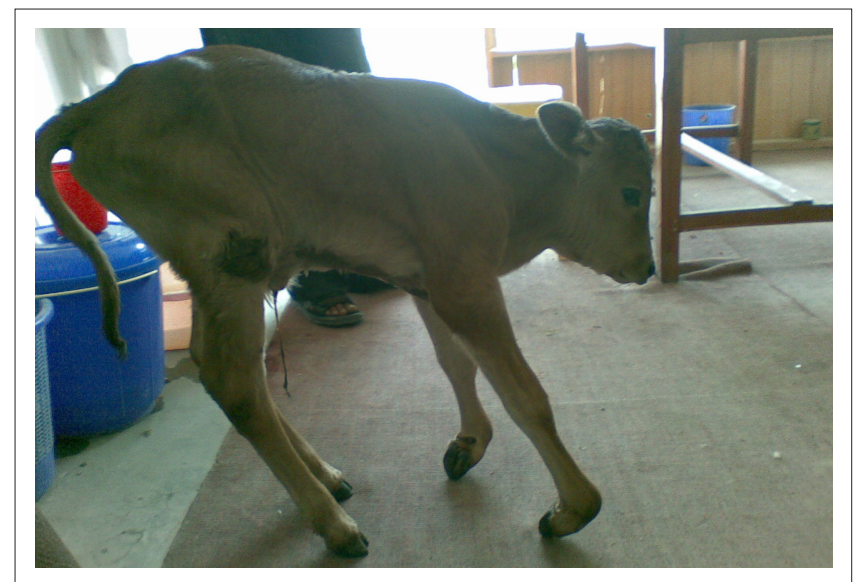

Source: Photo provided by Mujeeb R. Fazil

FIGURE 1: Photograph of a neonatal calf with moderate fetlock knuckling of the forelimb.

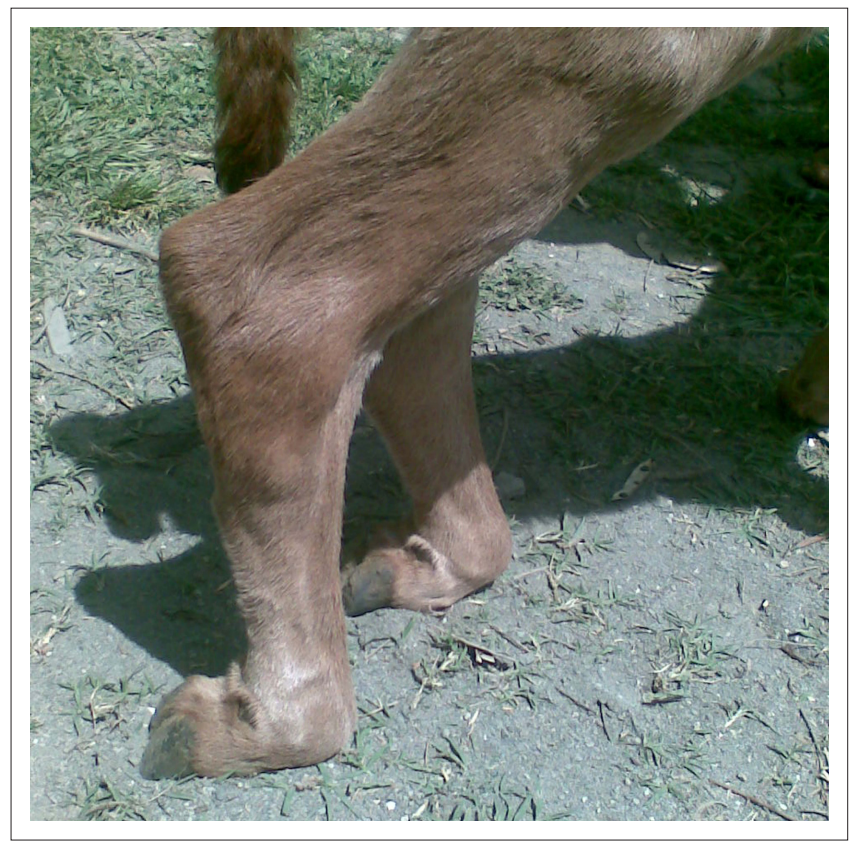

Source: Photo provided by Mujeeb R. Fazil

FIGURE 2: Photograph of a neonatal calf with moderate fetlock knuckling of the hindlimb.
For assessment of the angle at the affected fetlock joints, the calves were restrained without any premedication in lateral recumbency. The foot of the limb placed on the upper side was extended slightly and, using a protractor, the angle formed between a central longitudinal arbitrary line on the lateral aspect of the metacarpal or metatarsal bone with that of the central line of the corresponding foot was recorded (Sirin et al. 2014). The calves were then restrained on the contralateral side and the fetlock angle recorded in the same manner.

After injecting xylazine (Inj. Xylaxin, Indian Immunological Ltd.) $0.05 \mathrm{mg} / \mathrm{kg}$ intramuscularly (IM) or diazepam (Inj. Calmpose, Ranbaxy Laboratories Ltd. India), $0.1 \mathrm{mg} / \mathrm{kg} \mathrm{IV}$, the animals were restrained in lateral recumbency. A splint made from an appropriately sized well-padded wooden or polyvinyl chloride (PVC) pipe cut into a one-third or half semi-tubular shape was applied to the palmar/plantar aspect of the affected limbs of all the calves from the foot, excluding the claw, up to and including the knee/hock joint. All the calves were given a single dose of $2.0 \mathrm{mg} / \mathrm{kg}$ IM tolfenamic acid (Inj. Maxtol, Intas Pharmaceuticals Limited, India) as an analgesic.

The animals were then allotted randomly to one of the two equal groups $(n=7)$, Group I and Group II. The animals of Group I were given oxytetracycline (Inj. Terramycin, Pfizer India Ltd.) at $20.0 \mathrm{mg} / \mathrm{kg}$. The calculated dose of oxytetracycline was added to $250 \mathrm{~mL}$ of normal saline and infused IV daily for three consecutive days. The first dose was given at the hospital and the calf discharged. The remaining two doses were administered by the field veterinarian at the owner's premises. The animals of Group II received no additional medication.

The owners were advised to assist the calves in standing and suckling. They were also directed to monitor the proper position of the splint, and to apply three to four additional layers of bandage after carefully stretching the limb every alternate day. The owners were also instructed to remove the splints on day 10 and to encourage the animals to stand and walk for two more days before presentation at the hospital for further evaluation.

The proportion of the calves with knuckling among the neonates showing musculoskeletal congenital defects was calculated as a percentage. The mean \pm s.e. values of the fetlock angles were compared between the groups before treatment and within groups after 12 days or 20 days following institution of the treatment. The significance was calculated by $t$-test at $p \leq 0.01$.

\section{Results}

Musculoskeletal system deformities accounted for 34.3\% ( $n=24)$ of the 70 neonatal dairy calves that were presented with different congenital abnormalities (Table 1). Nineteen calves, ten male and nine female showed knuckling; they contsituted $27.1 \%$ of the total number of calves presented 
with congenital deformities. The majority (16) of these calves were crossbred Jersey calves. Two crossbred Holstein Friesian calves and one local non-descript calf also exhibited the condition. The body weight (mean \pm s.e.) and the age of the knuckling calves was $22.00 \mathrm{~kg} \pm$ $1.17 \mathrm{~kg}$ (range: $14 \mathrm{~kg}-35 \mathrm{~kg}$ ) and $7.11 \pm 1.16$ days (range: 1-25 days), respectively. All the calves except one were born unassisted. The dams of these calves had a mean \pm s.e. age of $6 \pm 0.62$ years (range: $3-12$ years) and their parity was $2.53 \pm 1.17$ (range: $1-5$ ). The owners reported that such abnormalities were not encountered in the earlier calves of these dams.

Forelimbs alone were affected in the greatest number (left $=16$, right $=14)$ of the calves, in which bilateral knuckling $(n=14)$ outnumbered unilateral $(n=2)$. Bilateral hindlimb knuckling was present in two calves. All four limbs were affected in one 3-day-old $16.0 \mathrm{~kg}$ crossbred Jersey female calf. The remaining five calves suffered from additional congenital conditions. Four had single additional defects (arthrogryposis $=2$, atresia ani $=1$ and brachygnathism $=$ 1) but one had multiple (arthrogryposis, kinked neck and tail) additional defects.

Only fetlock joints were involved in most $(n=16)$ of the calves (14 forelimb and 2 hindlimb). In two of these animals the carpal joints were also simultaneously involved. Carpal joints only were affected in another calf.

The mean \pm s.e. values of all the physiological and haematobiochemical parameters were within the normal range for

TABLE 1: Prevalence of congenital fetlock knuckling in neonatal dairy calves.

\begin{tabular}{lll}
\hline Calves & Number & $\mathbf{\%}$ \\
\hline Total congenital deformities & 70 & 100.0 \\
Musculoskeletal deformities & 24 & 34.3 \\
Knuckling & 19 & 27.1 \\
Knuckling & - & - \\
Among musculoskeletal deformities $(n=24)$ & 19 & 79.2 \\
Male $(n=19)$ & 10 & 52.6 \\
Female $(n=19)$ & 9 & 47.4 \\
Fetlock $(n=19)$ & 16 & 84.2 \\
Carpal $(n=19)$ & 1 & 5.3 \\
Fetlock plus carpal ( $n=19)$ & 2 & 10.5 \\
Without additional conditions $(n=19)$ & 4 & 73.7 \\
With additional conditions $(n=19)$ & 5 & 26.3 \\
Moderate fetlock alone & - & - \\
Total calves $(n=19)$ & 14 & - \\
Forelimb $(n=14)$ & 12 & 85.7 \\
Hindlimb $(n=14)$ & 02 & 14.3 \\
Fetlock angle & - & - \\
Minimum & $30^{\circ}$ & - \\
Maximum & $65^{\circ}$ & - \\
\hline
\end{tabular}

the neonatal calves; however, two animals in each group showed mild tachycardia ( $>150$ beats $/ \mathrm{min}$ ).

Whilst the animals were comfortably restrained in lateral recumbency, no difficulty was encountered in recording the fetlock joint angle. In calves of Group I, the mean \pm s.e. angle in the left and the right fetlock joints was $50.57^{\circ} \pm 4.20^{\circ}$ and $48.71^{\circ} \pm 2.37^{\circ}$, respectively. In Group II calves, the deflection angle was $50.86^{\circ} \pm 2.94^{\circ}$ and $48.71^{\circ} \pm 3.14^{\circ}$, respectively. The difference in the angles of the corresponding joints in calves of the two groups was not significant.

All the calves from both groups except one from Group I maintained the splints properly. One of the calves from Group II was lost to follow-up. Another owner had removed a wooden splint from the left leg of his calf on day 7 due to the development of pressure sores. These three calves were excluded from the study.

The outcome of the treatment in animals of both the groups is presented in Table 2. In animals of Group I, 9 out of 12 limbs of the affected six calves had resolved completely when examined 12 days after institution of the treatment. In these calves, the left and the right fetlock angles were $4.00^{\circ} \pm 2.27^{\circ}$ and $5.33^{\circ} \pm 3.03^{\circ}$, respectively (Table 3). Reduction in the angles, when compared to the pretreatment values, showed high statistical significance ( $p \leq$ 0.01). The affected feet showed full weight-bearing and no lameness was detected on progression. Deformity in one of the legs in three calves had reduced to $20^{\circ}, 24^{\circ}$ and $35^{\circ}$, respectively. In two of these calves, regular reinforcement of the splints had not been undertaken. Splints were reapplied for a further week. One of them recovered fully (increasing the success to $10 / 12 ; 83.3 \%$ ) but the remaining two animals still had $15^{\circ}$ and $20^{\circ}$ angle deformity on removal of the splints. They subsequently continued to show mild bending of the fetlock and lameness despite weight-bearing.

In animals of Group II, 7 out of 10 limbs of the six calves healed completely. In these calves, the left and the right fetlock angles were $4.20^{\circ} \pm 2.75^{\circ}$ and $6.80^{\circ} \pm 3.34^{\circ}$, respectively. In these calves, the reduction in the angles from pre-treatment values also showed high statistical significance $(p \leq 0.01)$. One of the remaining calves with mild deflection $\left(15^{\circ}\right)$ of both the limbs showed complete cure in one limb without subsequent reapplication of the splints. The other calf with a $20^{\circ}$ angle deviation of one

TABLE 2: Outcome of treatment in neonatal dairy calves with moderate fetlock knuckling.

\begin{tabular}{|c|c|c|c|c|c|c|}
\hline \multirow[t]{2}{*}{ Limbs } & \multicolumn{2}{|c|}{ Group I $(n=12)$} & \multicolumn{2}{|c|}{ Group II $(n=10)$} & \multicolumn{2}{|c|}{ Group II $(n=22)$} \\
\hline & $n$ & $\%$ & $n$ & $\%$ & $n$ & $\%$ \\
\hline Total calves & 7 & - & 7 & - & 14 & - \\
\hline Calves excluded subsequently & 1 & - & 2 & - & 3 & - \\
\hline Calves (limbs) evaluated at day 12 & 6 & - & 5 & - & 11 & - \\
\hline Limbs cured in 12 days & 09 & 75.0 & 07 & 70.0 & 16 & 72.7 \\
\hline Limbs cured at 20 days & 10 & 83.3 & 08 & 80.0 & 18 & 81.8 \\
\hline
\end{tabular}




\begin{tabular}{|c|c|c|c|c|c|c|}
\hline \multirow[t]{2}{*}{ Group } & \multicolumn{3}{|c|}{ Group I } & \multicolumn{3}{|c|}{ Group II } \\
\hline & Pre-treatment & Post-treatment & $t$-value & Pre-treatment & Post-treatment & $t$-value \\
\hline Left & $50.57 \pm 4.20$ & $4.00 \pm 2.27$ & $9.276^{*}$ & $50.86 \pm 2.95$ & $4.20 \pm 2.75$ & $11.096 *$ \\
\hline Right & $48.71 \pm 2.38$ & $5.33 \pm 3.03$ & $11.421 *$ & $48.71 \pm 3.15$ & $6.80 \pm 3.34$ & $8.960 *$ \\
\hline
\end{tabular}

$*, p \leq 0.01$

limb did not respond favourably during the next week. At the end of the study period, the deformity had fully resolved in $8 / 10(80.0 \%)$ limbs in the six calves.

\section{Discussion}

Congenital anomalies have been estimated to occur in $0.2 \%$ to $5.0 \%$ of calves (Distl \& Bahr 2005; Priester, Glass \& Waggoner 1970; Saperstein 2002). A prevalence of $6.37 \%$ among a total of 361 cattle presented for treatment of different congenital and acquired ailments was previously recorded from Kashmir (Fazili \& Syed 2003). From Kashmir it has been reported that $6.37 \%$ of the total 361 cattle presented for treatment comprised of congenital abnormalities (Fazili \& Syed 2003). The musculoskeletal system was involved in $34.3 \%$ of the calves presented for treatment of external congenital defects. Such defects were previously observed in only $24.0 \%$ of the total number of calves with congenital abnormalities (Leipold, Huston \& Dennis 1983; Samad 2002). Malformations of the distal limbs are among the most frequent congenital anomalies found in humans and animals (Fazili \& Syed 2003; Leipold \& Dennis 1987; Talamillo et al. 2005). Most of the calves in this study were crossbred Jerseys, which are currently the most predominant cattle breed in Kashmir.

The previous siblings of all the presented affected calves were reportedly normal at birth. All of the affected calves were single births. The aetiologic origins of contracted flexor tendons include inherited factors, in utero nutrition, malposition, and overcrowding caused by the size of the foetus relative to the dam (Anderson et al. 2008; Ferguson 1997).

Five of the 19 calves with knuckling showed arthrogryposis, atresia ani, brachygnathism, kinked neck and kinked tail as additional defects. According to one earlier report, contracted tendons may occur together with other congenital abnormalities such as cleft palate, dwarfism and arthrogryposis (Anderson et al. 2008).

The number of male calves with contracted flexors in the present study was slightly higher (53.2\%) than the females $(47.4 \%)$. In contrast to this finding, more females than males have been reported in a previous study involving only six calves (Simon et al. 2010).

The mean values of the various physiological parameters recorded in the present study's calves with knuckling of the fetlock were all in normal range (Piccione et al. 2010). Mild tachycardia recorded in two calves of both groups could be attributed to the distress experienced by these calves whilst trying to get up and move. Most of the calves with contracted flexors were presented within the first week of their life and had not developed any complications.

Forelimbs were involved in the majority of the calves with contraction of the flexor tendons. This finding is in accordance with earlier reports (Ferguson 1997; Krishnamurthy 1993; Verschooten et al. 1969). Most of the calves showed bilateral defects, as also reported by Weaver et al. (2005).

Goniometry is a simple, inexpensive, reliable, objective and non-invasive method (Govoni et al. 2012). For the first time, the fetlock joint angle in calves with contracted flexors has been recorded. The goniometric measurements of limb joints only proximal to the fetlock joints in healthy, awake Holstein Friesian calves restrained in lateral recumbency (Sirin et al. 2014) and standing sheep (Govoni et al. 2012) were recently reported. In the calves of the present study, the angle of the fetlock deflection varied from $30^{\circ}$ to $65^{\circ}$. According to Verschooten et al. (1969), the degree of contracture varies greatly. The mean angle of the corresponding sides in calves of both the groups was similar, thus making the comparison of the outcome valid.

The application of the splints was easy whilst the animals were properly sedated. Use of diazepam or xylazine with some muscle relaxant effect (Thurmon, Tranquilli \& Benson 1996) was helpful in stretching the contracted tendons. The purpose of splints is to align the limb so that the animal's body weight can stretch the tight tendons and ligaments; PVC is more frequently used than wooden splints. Good quality PVC piping is not only light but also has a concave inner surface that fits well to the contour of the limb. According to Ferguson (1997), they are simple and effective in calves. Wooden splints, although light in weight, may get dislodged or lead to pressure sores due to their flat contact surface. The toes are left un-bandaged to support some weight and to further stretch the tendons. It has been advised that the splints should be changed on a daily basis and applied with enough tension to produce a non-contracted limb (Ferguson 1997). In the present study, the owners were not directed to change the splints frequently due to fear of improper reapplication by them, but the need for repeated reinforcement and careful monitoring was stressed. One of the calves of Group II developed pressure sores under the splint. Scrupulous management of splints in neonates ensures avoidance of skin necrosis at potential pressure points (Weaver et al. 2005).

Non-steroidal anti-inflammatory drugs (NSAIDs) provide analgesia to the calf and are useful for decreasing the pain associated with stretching of the contracted soft tissue caused 
by weight-bearing, passive stretching exercises, splints or casts (Anderson et al. 2008). Only a single dose of an NSAID (tolfenamic acid) was used to avoid accentuation of the nephrotoxic effects of oxytetracycline.

The mechanism whereby oxytetracycline exerts its effect is unknown but it is most likely associated with a muscle relaxant effect (Madison et al. 1994). The safe dose of oxytetracycline in cattle is $6 \mathrm{mg} / \mathrm{kg}-11 \mathrm{mg} / \mathrm{kg}$ body weight (Papich \& Rivière 2009). According to Lairmore et al. (1984), tetracyclines should only be administered to cattle at recommended doses, to avoid problems of nephrotoxicosis. Oxytetracycline and tetracycline given to young animals can cause bones and teeth to become yellow, brown or grey, and high doses and long-term administration may delay bone growth and healing (Trent \& Redic-Kill 1997). In the present study, a high single dose of oxytetracycline was not used, to avoid toxicity. Following administration of oxytetracycline, kidney function tests could not be conducted. It was not possible to ascertain the discolouration of teeth and deleterious effects on bone growth and healing, as they require a longer postadministration period to develop.

Most flexural limb deformities resolve with persistent nonsurgical management (Anderson et al. 2008). The results of the present study indicated that moderate fetlock knuckling resolved completely in most $(80.0 \%)$ of the calves by proper application of splints. Only a marginal increase $(3.3 \%)$ in the positive outcome was noted with oxytetracycline administration at a low-toxicity dose. Considering the nephrotoxic potential of high doses of oxytetracycline in neonatal calves, the benefit of its use in knuckling calves needs to be confirmed.

Proper application and maintenance of the splints for 10 days was sufficient for managing most of the neonatal calves presented with moderate fetlock knuckling. According to Anderson et al. (2008), treatment of congenital flexural deformities should be initiated soon after recognition of the problem. As the animal gets older the contracted tissues become less responsive.

\section{Conclusion}

From this study it was concluded that:

- Forelimb bilateral knuckling is one of the most prevalent congenital musculoskeletal abnormalities affecting neonatal dairy calves.

- Most neonatal calves with moderate fetlock knuckling that present early for treatment can be managed satisfactorily with the proper application of the splints.

- Use of oxytetracycline at a low-toxicity dose $(20 \mathrm{mg} / \mathrm{kg}$ IV) daily for three consecutive days has a small additional beneficial effect in managing moderate fetlock knuckling.

Additional studies to ascertain the real benefit of using potentially toxic doses of oxytetracycline in neonatal calves with congenital knuckling are needed before continuing its routine use.

\section{Acknowledgements Competing interests}

The authors declare that they have no financial or personal relationship(s) that may have inappropriately influenced them in writing this article.

\section{Authors' contributions}

M.R.F. (Sher-e-Kashmir University of Agricultural Sciences and Technology of Kashmir) conceived the idea, undertook clinical management and assessment of the outcome of the cases, wrote and revised the manuscript. H.K.B. (Sher-eKashmir University of Agricultural Sciences and Technology of Kashmir) assisted M.R.F. in clinical management and evaluation of the outcome of the calves with fetlock knuckling. M.u.R.M. (Sher-e-Kashmir University of Agricultural Sciences and Technology of Kashmir) conducted biochemical evaluations of the animals. N.A.T. (Sher-eKashmir University of Agricultural Sciences and Technology of Kashmir) recorded anamnesis, conducted haematological evaluation of the animals and statistical analysis of data. A.H. (Sher-e-Kashmir University of Agricultural Sciences and Technology of Kashmir) recorded anamnesis and conducted haematological evaluation of the animal.

\section{References}

Anderson, D.E., Desrochers, A. \& St Jean, G., 2008, 'Management of tendon disorders in cattle', Veterinary Clinics of North America-Food Animal Practice 24, 551-566. http://dx.doi.org/10.1016/j.cvfa.2008.07.008

Distl, O. \& Bahr, C., 2005, 'Frequency of congenital anomalies in cattle: Results from the practice in comparison with literature', Deutsche Tierärztliche Wochenschrift $112,149-154$

Ducharme, N.G., 2004, 'Flexural deformities', in S.L. Fubini \& N.G. Ducharme (eds.) Farm Animal Surgery, 1st edn., pp. 486-489, Saunders, USA.

Fazili, M.R. \& Syed, F., 2003, 'Congenital deformities in calves: A retrospective study', Indian Journal of Veterinary Surgery 24, 114-115.

Ferguson, J.G., 1997, 'Surgery of the distal limb', in P.R. Greenough (ed.), Lameness in Cattle, 3rd edn., pp. 260-261, W.B. Saunders Company, Philadelphia.

Govoni, V.M., Rahal, S.C., Agostinhol, F.S., Conceição, R.T., Tsunemi, M.H. \& El-Warrak, A.O, 2012, 'Goniometric measurements of the forelimb and hindlimb joints in A.O, 2012, 'Goniometric measurements of the forelimb and hindlimb joints in
sheep', Veterinary and Comparative Orthopaedics and Traumatology 25, 297sheep', Veterinary and Comparative Orthopaedics
300. http://dx.doi.org/10.3415/VCOT-11-07-0098

Krishnamurthy, D., 1993, 'Tendons and ligaments', in R.P.S. Tyagi \& J. Singh (eds.), Ruminant Surgery, 1st edn., pp. 309-310, C.B.S. Publishers \& Distributors, Delhi.

Lairmore, M.D., Alexander, A.F., Powers, B.E., Milisen, W.B., Mcchesney, A.E. \& Spraker, T.S., 1984, 'Oxytetracycline-associated nephrotoxicosis in feedlot calves', Journal of the American Veterinary Medical Association 185, 793-795.

Leipold, H.W. \& Dennis, S.M., 1987, 'Cause, nature, effect and diagnosis of bovine congenital defects', Irish Veterinary News 9, 11-19.

Leipold, H.W., Hiraga, T. \& Dennis, S.M., 1993, 'Congenital defects of the bovine musculoskeletal system and joints', Veterinary Clinics of North America: Food Animal Practice 9, 93-104.

Leipold, H.W., Huston, K. \& Dennis, S.M., 1983, 'Bovine congenital defects', Advances in Veterinary Science and Comparative Medicine 27, 197-271.

Madison, J.B., Garber, J.L., Rice, B., Stumf, A.J., Zimmer, A.E. \& Ott, E.A., 1994, 'Effect of oxytetracycline on metacarpophalangeal and distal interphalangeal joint angles in newborn foals', Journal of the American Veterinary Medical Association 204, 246-249.

Papich, M.G. \& Rivière, J.E., 2009, 'Tetracycline antibiotics', in J.E. Rivière \& M.G. Papich (eds.), Veterinary Pharmacology \& Therapeutics, 9th edn., pp. 895-914, Wiley-Blackwell, USA.

Piccione, G., Casella, S., Pennisi, P., Giannetto, C., Costa, A. \& Caola, G., 2010 'Monitoring of physiological and blood parameters during perinatal and neonatal period in calves', Arquivo Brasileiro Médicina Véterinaria e Zootécnia 62, 1-12. http://dx.doi.org/10.1590/S0102-09352010000100001

Priester, W.A., Glass, A.G. \& Waggoner, N.S., 1970, 'Congenital defects in domesticated animals: General considerations', American Journal of Veterinary Research 31, 1871-1879.

Samad, M.A., 2002, 'Bovine congenital defects in Bangladesh', Bangladesh Veterinary Journal 36, 7-14. 
Saperstein, G., 2002, 'Congenital defects and hereditary disorders in ruminants', in B. Smith. (ed.), Large Animal Internal Medicine, 3rd edn., pp. 1465-1515, Mosby, St. Louis.

Simon, S., William, M.B.J., Rao, G.D., Sivashanker, R. \& Kumar, R.S., 2010, ‘Congenital malformations in ruminants and its surgical management', Veterinary World 3 , 118-119.

Sirin, O.S., Çelik, M.T., Özmen, A. \& Avki, S., 2014, 'Measurements of normal joint angles by goniometry in calves', Veterinary and Comparative Orthopaedics and Traumatology 27, 120-123. http://dx.doi.org/10.3415/VCOT-13-04-0046

Talamillo, A., Bastida, M.F., Fernandez-Teran, M. \& Ros, M.A., 2005, 'The developing limb and the control of the number of digits', Clinical Genetics 67, 143-153. http://dx.doi.org/10.1111/j.1399-0004.2005.00404.x
Thurmon, J.C., Tranquilli, W.J. \& Benson, G.J., 1996, 'Preanesthetics and anesthetic adjuncts', in Lumb \& Jones' Veterinary Anesthesia, 3rd edn., pp. 183-209, 186194, Williams \& Williams, Baltimore.

Trent, A.M. \& Redic-Kill, K.A., 1997, 'Clinical pharmacology', in P.R. Greenough (ed.), Lameness in Cattle, 3rd edn., pp. 56-70, W.B. Saunders Company, Philadelphia.

Verschooten, F., De Moor, A., Desmet, P., Watte, R. \& Gunst, O., 1969, 'Surgical treatment of congenital arthrogryposis of the carpal joint associated with contraction of the flexor tendons in calves', Veterinary Record 85, 140-171. http://dx.doi.org/10.1136/vr.85.6.140

Weaver, A.D., St Jean, G. \& Steiner, A., 2005, Bovine Surgery and Lameness, 2nd edn., Blackwell Publishing Ltd, Oxford. http://dx.doi.org/10.1002/9780470751138 